\title{
Pregnancy of Unknown Location: The Value of Frozen Section Analysis and Its Relation to Beta-hCG Levels and Endometrial Thickness
}

\author{
Marwan Odeh ${ }^{1,2}$ \\ Ayat Qasoum ${ }^{1} \quad$ Rene Tendler ${ }^{1}$ \\ Mohamad Kais ${ }^{1}$ Rola Khamise Farah ${ }^{1}$ \\ Jacob Bornstein ${ }^{1,2}$ \\ ${ }^{1}$ Department of Obstetrics and Gynecology, Galilee Medical Center, \\ Nahariya, Israel \\ ${ }^{2}$ Azrieli Galilee Faculty of Medicine, Bar Ilan University, Safed, Israel \\ Address for correspondence Marwan Odeh, MD, Department of \\ Obstetrics and Gynecology, Galilee Medical Center, POB 21, Nahariya \\ 22100, Israel (e-mail: marwan20@bezeqint.net).
}

Rev Bras Ginecol Obstet 2019;41:142-146.

\begin{abstract}
Objective Frozen section examination is a rapid method for identifying products of conception in endometrial curetting, yet its accuracy is inconclusive. The purposes of this study is to determine the accuracy of frozen section analysis of endometrial curetting in pregnancies of unknown location, and to verify the relation of $\beta$-human chorionic gonadotrophin (hCG) level and endometrial thickness to the assessed accuracy.

Methods We reviewed data from January 2009 to December 2014 of diagnostic curettages from women with suspected ectopic pregnancies sent for frozen section examination at a medical center. A frozen section diagnosis was considered accurate if it concurred with the final pathologic diagnosis.

Results Of 106 frozen section studies, the diagnosis was accurate in 94 (88.7\%). Of 79 specimens interpreted as negative on frozen sections (no products of conception noted), 9 (11.4\%) were positive on final pathologic review. Three of the $27(11.1 \%)$ specimens interpreted as positive by a frozen section failed to demonstrate products of

Keywords

- ectopic pregnancy

- frozen section

- pregnancy of unknown location

- $\beta$-hCG

- endometrial thickness conception on a final pathologic section. The sensitivity of frozen sections in the diagnosis of ectopic pregnancy was $72.7 \%$, specificity $95.9 \%$, positive predictive value $88.9 \%$, negative predictive value $88.6 \%$, and accuracy $88.6 \%$. A statically significant correlation was found between $\beta$-hCG level and high accuracy of the frozen section technique $(p<0.001)$. No correlation was found between endometrial thickness and the accuracy of the frozen section technique.

Conclusion The accuracy of frozen section examination was high and was found to correlate with $\beta$-hCG level, but not with endometrial thickness.
\end{abstract}

\section{Introduction}

Ectopic pregnancy can be identified early by the widespread use of transvaginal ultrasonography with high frequency probes, together with the use of sensitive quantitative measurements of serum human chorionic gonadotropin (hCG). ${ }^{1-7}$ Confirmation

(1) Marwan Odeh's ORCID is https://orcid.org/0000-0002-1616-1381. of the presence of intrauterine pregnancy by transvaginal ultrasonography is a highly accurate method of exclusion of an ectopic pregnancy, and in most cases has replaced diagnostic curettage as a cornerstone for ruling out or ruling in an ectopic pregnancy. ${ }^{8}$ However, in certain situations ultrasonography might result in diagnostic uncertainty, in which case an endometrial biopsy may still be necessary to distinguish between abnormal intrauterine and ectopic pregnancies. received

July 12,2018

accepted

October 9, 2018

published online

December 12, 2018
DOI https://doi.org/

10.1055/s-0038-1676123. ISSN 0100-7203.
Copyright (e) 2019 by Thieme Revinter

Publicações Ltda, Rio de Janeiro, Brazil
License terms

(c) (i) 
Frozen section evaluation of uterine curetting is performed in certain instances of pregnancy of unknown location (PUL), to rule out ectopic pregnancy. If chorionic villi are identified in utero, an ectopic gestation is essentially ruled out (except for rare cases of heterotopic pregnancies) and no further treatment is needed. If villi are not detected, this may reflect an ectopic pregnancy, although the patient may also have expelled all intrauterine villi. The absence of chorionic villi on endometrial frozen section may lead to laparoscopy, laparotomy, salpingectomy or methotrexate therapy, despite the fact that an ectopic pregnancy is not always present. ${ }^{8}$ Therefore, diagnosis using the frozen section technique performed on endometrial material shortly after curettage and after conception products have been identified can dramatically decrease the time needed to rule out the presence of an ectopic pregnancy. Such diagnosis also avoids the undesired administration of methotrexate to women with intrauterine pregnancy.

The accuracy of endometrial biopsies using the frozen section technique has not been thoroughly evaluated. No systematic reviews have been conducted on this topic.

We found three relevant articles in PubMed and MedLine databases. Two of them highly recommended the use of frozen section examination as an accurate method for identifying products of conception in endometrial curetting. In their analysis of 87 cases in which frozen section assessment of an endometrial curettage specimen was performed, Spandorfer et $\mathrm{al}^{9}$ found that 81 (93.1\%) were accurate. Only one woman was misdiagnosed and did not have an ectopic pregnancy. In a study conducted at our medical center, frozen section analysis had a sensitivity of $78 \%$, specificity of $98 \%$, positive predictive value of $95 \%$ and a negative predictive value of $93 \% .{ }^{10}$ In that study of 70 frozen sections, 63 (90\%) were accurate. Of 50 specimens interpreted as negative on frozen sections, 6 (12\%) contained conception products on final pathologic review. One of the $20(5 \%)$ specimens interpreted as positive by a frozen section failed to demonstrate products of conception on a final pathologic section. The sensitivity of frozen sections in the diagnosis of ectopic pregnancy was $76 \%$; specificity, $98 \%$; positive predictive value, 95\%; negative predictive value, $88 \%$, and accuracy, $90 \%$. The accuracy of frozen section diagnoses was analyzed and stratified by preoperative serum hCG concentration. The cut-off point used for serum hCG was 1,000 $\mathrm{IU} / \mathrm{l}^{10}{ }^{10}$ The percentage of inaccurate frozen section diagnoses was greater in the subgroup with higher serum hCG values (12.5\%) than in the subgroup with lower values (9.3\%). However, the difference between the two groups was not statistically significant.

In contrast to these two studies, Heller et al $^{11}$ concluded that frozen section evaluation of uterine curetting can produce false negative diagnosis, and that this should be considered in the operative planning of women with suspected ectopic pregnancy. They reviewed 36 cases, of which 13 showed evidence of intrauterine pregnancy on final permanent sections. Five false negatives were identified in which no villi had been identified on a frozen section, but villi or evidence of an implantation site had been noted on final pathologic sections. The sensitivity of frozen sections in the diagnosis of ectopic pregnancy was $62 \%$.
The purpose of the current study was to determine the accuracy of frozen section analysis in cases of pregnancy of unknown location, and the relation of this assessment of accuracy to $\beta$-hCG level and endometrial thickness.

\section{Methods}

We performed a retrospective analysis of the Department of Obstetrics and Gynecology database in Galilee Medical Center from January 2009 to December 2014. In women with PUL, a diagnostic curettage was performed and the material from the curetting was sent for frozen section examination. PUL was defined as the situation of a positive pregnancy test with no signs of intra- or extrauterine pregnancy on transvaginal sonography. ${ }^{12}$ Curettage was performed only in cases with a plateau of $\beta$-hCG levels in at least two consecutive examinations; or $\beta$-hCG of more than $2,000 \mathrm{mIU} / \mathrm{ml}$ in 2 sequential measurements, 48 hours apart, a rise of less than 1.66 in $\beta$ levels $(48 \mathrm{~h} / 0<1.66)$ and no evidence of intra or extrauterine pregnancy.

In the department of pathology, frozen sections were prepared from endometrial curetting, and blood clots were separated from the specimen macroscopically before freezing. The tissue was embedded in optimal cutting temperature aqueous medium and then it was frozen in liquid isopentane at $-25^{\circ} \mathrm{C}$. The frozen tissue was cut on a cryostat, and 5 to $9 \mu \mathrm{m}$ sections of tissue were transferred to a glass slide at room temperature, stained with hematoxylin and eosin, and a cover slip was applied. The remaining frozen material was thawed and processed for routine paraffin fixation. Cases with negative result for chorionic villi have the samples supplied with $\beta$ hCG, Vimentin and Pan Keratin A1/A3 immunohistochemical staining (Zymed\#, Zymed Laboratories Inc., San Francisco, CA, USA). The entire frozen section process took no longer than 20 minutes, including microscopic inspection of the section.

The main variables investigated were frozen section diagnosis and final pathologic diagnosis, both variables according to the presence or absence of products of conception. Frozen section diagnosis was considered accurate if it concurred with the final pathologic diagnosis. Clinical and epidemiological data were also investigated, including age, week of gestation, $\beta$-hCG level, and endometrial thickness before the curettage took place.

Quantitative data, such as age, week of gestation, $\beta$-hCG level, and endometrial thickness, are described by mean and standard deviation, and by median and range. Qualitative data are presented as frequencies and percentages. This includes calculations of accuracy, sensitivity, specificity, and positive and negative predictive values. Accuracy, which was assessed as the concurrence or discrepancy between frozen section diagnosis and final pathologic diagnosis, was calculated for subgroups according to- $\beta$ hCG level determined by receiver operator characteristic (ROC) curves. The cut-off point used was a serum hCG level of 1,000 IU/l. This level was chosen based on the 'discriminatory zone' values reported in the literature. This concept was developed by Kadar et $\mathrm{al}^{13}$ to determine the serum hCG level at which a 
sac should be seen on ultrasound examination. According to this concept, if the serum hCG level is above the 'discriminatory zone' and an intrauterine gestational sac is not seen, the pregnancy is abnormal, has aborted, or is in an ectopic location. Using vaginal sonography to detect the sac, the range of 'discriminatory zones' reported extends from 600 to $1,025 \mathrm{mIU} / \mathrm{ml}^{14-17}$

The t-test was used to examine the relation between the accuracy of frozen section and both $\beta$ hCG level and endometrial thickness. A statistically significant result was defined if $p<0.05$. The study was approved by the Institutional Review Board (Helsinki Committee) of Galilee Medical Center.

\section{Results}

Data of 106 women were analyzed. - Table 1 presents demographic and clinical data. Frozen sections were positive for products of conception in 27 (26\%), whereas final pathological examination was positive in 33 (31\%) (-Fig. 1). The accuracy of frozen section analysis in detecting products of conception, when compared with the final pathological diagnosis, was $88.7 \%$. The correlation between frozen section and final pathological diagnosis was statistically significant $(p<0.001)$, with phi $=0.729$ (high strength). Of the 106 frozen section studies the diagnosis was accurate in 94 (88.7\%) and inaccurate in $12(11.3 \%)$. Of the 79 specimens interpreted as negative on frozen sections (no products of conception noted), 9 (11.4\%) were found to contain conception products on final pathologic review. Three of the 27
Table 2 Results of frozen section and pathological examination

\begin{tabular}{|l|l|l|l|l|}
\hline \multicolumn{2}{|c|}{} & \multicolumn{2}{|l|}{$\begin{array}{l}\text { Pathological } \\
\text { diagnosis }\end{array}$} \\
\cline { 3 - 5 } & Negative & Positive \\
\hline $\begin{array}{l}\text { Frozen } \\
\text { section } \\
\text { diagnosis }\end{array}$ & Negative & $\begin{array}{l}\text { Number } \\
\text { of cases }\end{array}$ & 70 & 9 \\
\cline { 3 - 5 } & $\%$ & $95.9 \%$ & $27.3 \%$ \\
\cline { 3 - 5 } & Positive & $\begin{array}{l}\text { Number } \\
\text { of cases }\end{array}$ & 3 & 24 \\
\cline { 3 - 5 } & $\%$ & $4.1 \%$ & $72.7 \%$ \\
\hline \multirow{2}{*}{ Total } & $\begin{array}{l}\text { Number } \\
\text { of cases }\end{array}$ & 73 & 33 \\
\cline { 3 - 5 } & $\%$ & $100 \%$ & $100 \%$ \\
\hline
\end{tabular}

(11.1\%) specimens interpreted as positive by a frozen section failed to demonstrate products of conception on a final pathologic section. All three women were not discharged and received followed-up because of the low percentage, but yet very dangerous misdiagnosis of a normal intrauterine pregnancy in cases of ectopic pregnancy.

As presented in - Table 2, the sensitivity of frozen section analysis in the diagnosis of ectopic pregnancy was $72.7 \%$, specificity $95.9 \%$, positive predictive value $88.9 \%(24 / 27)$ and negative predictive value $88.6 \%$ (70/79) (-Table 2 ). The median $\beta$-hCG level was lower for cases in which the frozen section diagnosis was accurate than for cases of inaccuracy (-Table 3 ).

Table 1 Demographic and clinical data of 106 women with suspected ectopic pregnancies

\begin{tabular}{|l|l|l|l|l|}
\hline Variables & $\begin{array}{l}\text { Number of records found } \\
\text { N (\%) }\end{array}$ & Mean \pm SD & \multicolumn{2}{l|}{ Range } \\
\cline { 3 - 5 } & & & Minimum & Maximum \\
\hline Age (years) & $(99 \%) 105$ & $31.4 \pm 5.6$ & 20 & 44 \\
\hline Week of gestation & $(93 \%) 99$ & $6.2 \pm 1.6$ & 3 & 12 \\
\hline Beta-hCG level (mIU/ml) & $(100 \%) 106$ & $6,394 \pm 22,988.4$ & 5 & 159,000 \\
\hline Endometrial thickness (mm) & $(81 \%) 86$ & $11.75 \pm 6$ & 1 & 26 \\
\hline
\end{tabular}

Abbreviation: SD, standard deviation.

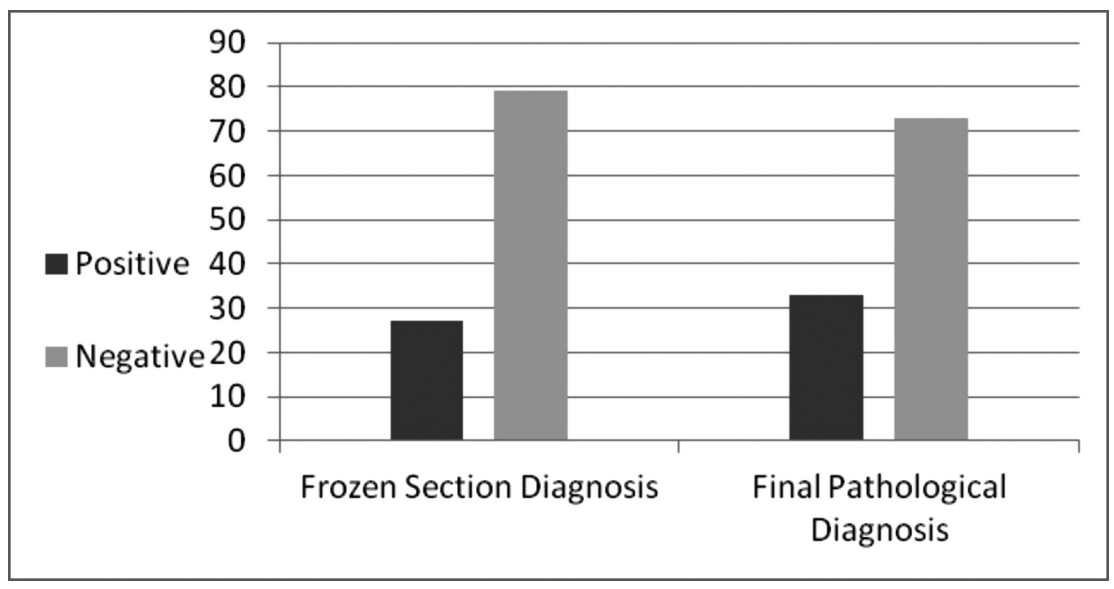

Fig. 1 Results of frozen section and final pathological examination. 
Table 3 Beta-hCG level according to the accuracy of frozen section and pathological results

\begin{tabular}{|l|l|l|l|l|l|l|l|}
\hline \multirow{2}{*}{} & Accuracy of FS and pathological diagnosis & \multicolumn{2}{|l|}{$\begin{array}{l}\text { Number of } \\
\text { cases }\end{array}$} & Median & Minimum & Maximum & Pa \\
\cline { 3 - 5 } & & Valid & Missing & & & \\
\hline \multirow{2}{*}{ Beta-hCG level } & Inaccurate & 12 & 0 & $1,551.5$ & 422 & 10,115 & 0.01 \\
\cline { 2 - 8 } & Accurate & 94 & 0 & 493.52 & 5 & 159,000 & 1 -sided \\
\hline
\end{tabular}

Abbreviation: FS, Frozen section.

a P-value according to Wilcoxon rank sum test.

Table 4 Endometrial thickness according to the accuracy of frozen section and pathological results

\begin{tabular}{|c|c|c|c|c|c|c|c|}
\hline & \multirow{2}{*}{$\begin{array}{l}\text { Accuracy of FS and } \\
\text { pathological diagnosis }\end{array}$} & \multicolumn{3}{|c|}{ Number of cases } & \multirow[t]{2}{*}{ Minimum } & \multirow[t]{2}{*}{ Maximum } & \multirow[t]{2}{*}{$P a$} \\
\hline & & Valid & Missing & Mean \pm SD & & & \\
\hline \multirow{2}{*}{$\begin{array}{l}\text { Endometrial } \\
\text { thickness }\end{array}$} & Inaccurate & 11 & 1 & $14.5 \pm 5.4$ & 8 & 25 & 0.101 \\
\hline & Accurate & 75 & 19 & $11.3 \pm 6$ & 1 & 26 & 2-sided \\
\hline
\end{tabular}

Abbreviation: FS, Frozen section; SD, standard deviation.

a P-value according to Wilcoxon rank sum test.

Table 5 The accuracy of frozen section diagnosis according to preoperative serum hCG concentration: higher hCG concentration was associated with higher accurate diagnosis of the frozen section $(p<0.001)$

\begin{tabular}{|l|l|l|l|}
\hline $\begin{array}{l}\text { hCG level } \\
(\mathrm{mIU} / \mathrm{ml})\end{array}$ & $\begin{array}{l}\text { Number } \\
\text { of cases }\end{array}$ & $\begin{array}{l}\text { Diagnoses } \\
\text { concur } \\
\%\end{array}$ & $\begin{array}{l}\text { Diagnoses } \\
\text { differ } \\
\%\end{array}$ \\
\hline$<1000$ & 64 & $\begin{array}{l}60 \\
93.7 \%\end{array}$ & $\begin{array}{l}4 \\
6.3 \%\end{array}$ \\
\hline$>1000$ & 42 & 34 & 8 \\
& & $81 \%$ & $19 \%$ \\
\hline
\end{tabular}

This correlation was statically significant $(p=0.01$ ). Endometrial thickness was greater for cases that showed discrepancy between frozen section analysis and pathological diagnosis; however, the difference was not statically significant (-Table 4). More frozen section diagnoses were accurate in cases with preoperative serum hCG concentration $<1,000$ $\mathrm{mIU} / \mathrm{ml}$ than in cases with hCG concentration $>1,000 \mathrm{mIU} /$ $\mathrm{ml}, p<0.001$ ( - Table 5). According to ROC: area under curve $=0.696, p=0.001$, confidence interval $(\mathrm{CI})$ was $95 \%(0.583$, 0.809 ). For $\beta$-hCG level $=1,000 \mathrm{mIU} / \mathrm{ml}$, the sensitivity of accurate diagnosis was $61 \%$, and the specificity was $70 \%$.

\section{Discussion}

The management of PUL was thoroughly revised by Barnhart et al. $^{18}$ In their review, several management protocols were suggested, including histologic confirmation of the diagnosis in some cases. ${ }^{18}$ Our study supports the use of frozen section technique as a rapid and accurate method of identifying products of conception on endometrial curettage. The $88.7 \%$ accuracy of frozen section analysis we reported is similar to that demonstrated by Barak et al. ${ }^{10}$ The positive and negative predictive values ( $88.9 \%$ and $88.6 \%$, respectively), though high, are of limited strength due to the retrospective design of the analysis.

Of the incorrect diagnosis in our study, most were false negatives ( 9 of 106 cases), in which women were erroneously diagnosed by the frozen section technique with the absence of intrauterine pregnancy. In all nine cases, women started methotrexate therapy.

Although the single dose methotrexate protocol has fewer side-effects than the earlier multiple dose therapy, this antimetabolite treatment is not completely safe and has its drawbacks. Such drawbacks are bone marrow suppression and delaying the next pregnancy to ensure that the medication has been cleared from the organism, since methotrexate is associated with birth defects. Thus, methotrexate should be initiated only after the confirmation of a pathological diagnosis of ectopic pregnancy or after measuring $\beta$-hCG level at least once more after the procedure.

There were three false-positive diagnoses among our cohort, in which women were erroneously thought to have villi in the frozen section specimen and were thus misdiagnosed as not having an ectopic pregnancy. A possible explanation for this error is that part of a trophoblastic villus from the tubal pregnancy was shed into the uterus. As the amount of tissue may have been minimal, it could have been included in the frozen section specimen only, and not in the final pathology material. A false positive result poses the highest risk since a woman could be discharged from the hospital with an ectopic pregnancy that could rupture and be fatal. Therefore, even if the frozen section detects products of conception, and the woman is hemodynamically stable, a thorough monitoring of $\beta$-hCG should be done to ensure a downward trend. The occurrence of false positive and false negative results emphasizes the need to confirm the frozen section diagnosis with a definitive pathologic examination.

Beta-hCG was lower among those subjects with accurate frozen section diagnosis; this included both true positive ( 24 of 106) and true negative (70 of 106) cases. A possible 
explanation is that true negative cases comprise $75 \%$ of the accurate cases (70 of 94 cases); since this represents the absence of intrauterine pregnancy, $\beta$-hCG level is expected to be low. To improve the accuracy of the pregnancy location Seeber et al. ${ }^{19}$ suggested the use of a redefined hCG curves, and yet $12 \%$ of the patients with ectopic pregnancy were not diagnosed. The results of this study ${ }^{19}$ also emphasize the need to rely on more than one criterion to diagnose ectopic pregnancy, such as progesterone plasma concentrations. ${ }^{20}$

We initially hypothesized that greater endometrial thickness will have a significant correlation with frozen section diagnosis, because thickened endometrium will provide more material for frozen section evaluation. Our results did not show such relationship. We suggest, as an explanation for this result, that endometrial thickness, as measured by ultrasound, includes in most cases blood clots and not only products of conception.

The frozen section method provides a rapid means of diagnosing ectopic pregnancy. Advantages of this technique include early institution of therapy and reduction in the hospitalization period, with its inherent costs in cases of suspected abnormal intrauterine pregnancy. The patient can be discharged once the diagnosis of conception products is obtained by frozen section, and the uterus is evacuated. However, the adherence to strict criteria of diagnosing an abnormal intrauterine pregnancy or ectopic pregnancy is important to avoid the unintended termination of a wanted pregnancy. ${ }^{21}$

\section{Conclusion}

In conclusion, frozen section examination is a rapid and mostly accurate method of diagnosing products of conception in endometrial curetting. We report a statically significant correlation between lower $\beta$-hCG levels and high accuracy of the frozen section technique. Such a correlation was not displayed between endometrial thickness and the accuracy of the frozen section technique. The results of our study suggest that implementation of this technique in the clinical management of an ectopic pregnancy enables more rapid diagnosis, facilitates earlier institution of treatment and shortens the period of hospitalization.

\section{Conflicts of Interest}

This study was part of the requirements for the degree of Doctor of Medicine by Azrieli Galilee Faculty of Medicine, Bar Ilan University (Safed, Israel).

\section{References}

1 Lipscomb GH, Stovall TG, Ling FW. Nonsurgical treatment of ectopic pregnancy. N Engl J Med 2000;343(18):1325-1329 Doi: 56/NEJM200011023431807

2 Aboulghar MA, Mansour RT, Serour GI. Transvaginal injection of potassium chloride and methotrexate for the treatment of tubal pregnancy with a live fetus. Hum Reprod 1990;5(07):887-888 Doi: 10.1093/oxfordjournals.humrep.a137204

3 Altaras M, Cohen I, Cordoba M, Ben-Nun I, Ben-Aderet N. Treatment of an interstitial pregnancy with actinomycin D. Case report. Br J
Obstet Gynaecol 1988;95(12):1321-1323 Doi: 10.1111/j.14710528.1988.tb06826.x

4 Gazvani MR, Emery SJ. Mifepristone and methotrexate: the combination for medical treatment of ectopic pregnancy. Am J Obstet Gynecol 1999;180(6 Pt 1):1599-1600 Doi: 10.1016/ S0002-9378(99)70067-0

5 Kenigsberg D, Porte J, Hull M, Spitz IM. Medical treatment of residual ectopic pregnancy: RU 486 and methotrexate. Fertil Steril 1987;47(04):702-703 Doi: 10.1016/S0015-0282(16)59126-2

6 Lindblom B, Hahlin M, Lundorff P, Thorburn J. Treatment of tubal pregnancy by laparoscope-guided injection of prostaglandin F2 alpha. Fertil Steril 1990;54(03):404-408 Doi: 10.1016/S00150282(16)53752-2

7 Lang PF, Weiss PA, Mayer HO, Haas JG, Hönigl W. Conservative treatment of ectopic pregnancy with local injection of hyperosmolar glucose solution or prostaglandin-F2 alpha: a prospective randomised study. Lancet 1990;336(8707):78-81 Doi: 10.1016/ 0140-6736(90)91593-Y

8 Barnhart K, Mennuti MT, Benjamin I, Jacobson S, Goodman D, Coutifaris C. Prompt diagnosis of ectopic pregnancy in an emergency department setting. Obstet Gynecol 1994;84(06): 1010-1015

9 Spandorfer SD, Menzin AW, Barnhart KT, LiVolsi VA, Pfeifer SM. Efficacy of frozen-section evaluation of uterine curettings in the diagnosis of ectopic pregnancy. Am J Obstet Gynecol 1996;175 (3 Pt 1):603-605 Doi: 10.1053/ob.1996.v175.a73599

10 Barak S, Oettinger M, Perri A, Cohen HI, Barenboym R, Ophir E. Frozen section examination of endometrial curettings in the diagnosis of ectopic pregnancy. Acta Obstet Gynecol Scand 2005;84(01):43-47 Doi: 10.1111/j.0001-6349.2005.00531.x

11 Heller DS, Hessami S, Cracchiolo B, Skurnick JH. Reliability of frozen section of uterine curettings in evaluation of possible ectopic pregnancy. J Am Assoc Gynecol Laparosc 2000;7(04): 519-522 Doi: 10.1016/S1074-3804(05)60366-0

12 Condous G, Timmerman D, Goldstein S, Valentin L, Jurkovic D, Bourne T. Pregnancies of unknown location: consensus statement. Ultrasound Obstet Gynecol 2006;28(02):121-122 Doi: 10.1002/uog.2838

13 Kadar N, DeVore G, Romero R. Discriminatory hCG zone: its use in the sonographic evaluation for ectopic pregnancy. Obstet Gynecol 1981;58(02):156-161

14 Goldstein SR, Snyder JR, Watson C, Danon M. Very early pregnancy detection with endovaginal ultrasound. Obstet Gynecol 1988;72 (02):200-204

15 Timor-Tritsch IE, Rottem S, Thaler I. Review of transvaginal ultrasonography: a description with clinical application. Ultrasound Q 1988;6:1-34

16 Bernaschek G, Rudelstorfer R, Csaicsich P. Vaginal sonography versus serum human chorionic gonadotropin in early detection of pregnancy. Am J Obstet Gynecol 1988;158(3 Pt 1):608-612

17 Peisner DB, Timor-Tritsch IE. The discriminatory zone of beta-hCG for vaginal probes. J Clin Ultrasound 1990;18(04):280-285 Doi: $10.1002 /$ jcu. 1870180411

18 Barnhart K, van Mello NM, Bourne T, et al. Pregnancy of unknown location: a consensus statement of nomenclature, definitions, and outcome. Fertil Steril 2011;95(03):857-866 Doi: 10.1016/j. fertnstert.2010.09.006

19 Seeber BE, Sammel MD, Guo W, Zhou L, Hummel A, Barnhart KT. Application of redefined human chorionic gonadotropin curves for the diagnosis of women at risk for ectopic pregnancy. Fertil Steril 2006;86(02):454-459 Doi: 10.1016/j.fertnstert.2005.12.056

20 Verhaegen J, Gallos ID, van Mello NM, et al. Accuracy of single progesterone test to predict early pregnancy outcome in women with pain or bleeding: meta-analysis of cohort studies. BMJ 2012; 345:e6077 Doi: 10.1136/bmj.e6077

21 Condous G, Kirk E, Lu C, et al. There is no role for uterine curettage in the contemporary diagnostic workup of women with a pregnancy of unknown location. Hum Reprod 2006;21(10):2706-2710 Doi: 10.1093/humrep/del223 